\title{
Life Kinetik Training to Increase Concentration and Skills in Playing Football
}

\author{
Komarudin*, Patriana Nurmansyah Awwaludin, Yusuf Hidayat, Novrizal Achmad Novan \\ Faculty of Sport Education and Health, Universitas Pendidikan Indonesia, Bandung, Indonesia
}

Received May 9, 2021; Revised June 16, 2021; Accepted July 20, 2021

\section{Cite This Paper in the following Citation Styles}

(a): [1] Komarudin, Patriana Nurmansyah Awwaludin, Yusuf Hidayat, Novrizal Achmad Novan, "Life Kinetik Training to Increase Concentration and Skills in Playing Football," International Journal of Human Movement and Sports Sciences, Vol. 9, No. 4A, pp. 53 - 58, 2021. DOI: 10.13189/saj.2021.091309.

(b): Komarudin, Patriana Nurmansyah Awwaludin, Yusuf Hidayat, Novrizal Achmad Novan (2021). Life Kinetik Training to Increase Concentration and Skills in Playing Football. International Journal of Human Movement and Sports Sciences, 9(4A), 53 - 58. DOI: 10.13189/saj.2021.091309.

Copyright $C 2021$ by authors, all rights reserved. Authors agree that this article remains permanently open access under the terms of the Creative Commons Attribution License 4.0 International License

\begin{abstract}
This study examines the influence difference between Life Kinetik training and conventional training on increasing concentration and football playing skills. This exercise has not been widely applied in the training process to improve psychological abilities and football skills. The method used in this study is an experiment with 90 football athletes subject in one of the state universities in Indonesia. Through random selection subjects, 40 people were taken, and the random assignment of subjects was divided into two, namely the experimental and control groups of 20 people each. The instrument to measure concentration was used, the Concentration Grid Test (CGT), and the instrument to measure football playing skills, the Games Performance Assessment Instrument (GPAI). This study uses a pretest-posttest control group design. The data analysis technique used the non-parametric Mann Whitney Test with SPSS version 21. The results showed significant differences in the effect of Life Kinetik training and conventional training on increasing concentration and football playing skills. Life Kinetik Training is better than conventional training for increasing concentration and soccer-playing skills. The authors would like to recommend coaches and athletes in the football to use Life Kinetik in the training process because it can improve athlete concentration and football playing skills.
\end{abstract}

Keywords Concentration, Football Playing Skills, Life Kinetik

\section{Introduction}

Peak performance is determined by several predictor variables: physical abilities, techniques, tactics, psychological [1], environmental factors, and cognitive abilities [2]. Psychological abilities are an important part of achieving peak performance [3] and is a fundamentally important factor of any exercise program [4]. Athletes who have psychological maturity will face all psychological challenges in carrying out their duties both in training situations and in competitive situations.

The development of the field of psychology has steadily increased over the past 20 years with a growing number of sports psychology or mental skills training programs being developed for college-level and elite athletes and teams [5]. Athletes who have psychological maturity can control all problems, face various challenges, have confidence in themselves, and have a strong commitment to doing their job. Specifically, in football, athletes who have psychological maturity will have the ability to control all problems on the field, including controlling their body, able to master the ball well, can make decisions quickly, precisely, and accurately, and are also able to shoot at goal accurately. Football players have positive and negative psychological momentum where positive decisions must overcome negative conditions [6]. These conditions can only be mastered by athletes when not supported by physical conditions, skills, intelligence, and the quality of the central nervous system to control complex tasks [7].

The complexity of the motion that exists in the game of 
football will be mastered by athletes when athletes have multiple abilities (multitasking). As an illustration, Maradona is a legendary Argentine football player with multiple abilities. He has intelligence in moving (sense of intelligent movement) and can move quickly and avoid all obstacles that prevent it. The ability possessed by a legendary, it turns out one of them can be trained with Life Kinetik's practice.

Life Kinetik Training is a form of cognitive-motor coordination training. This training is a combination of three aspects of exercise: motion exercise training, cognitive challenge training, and visual perception training [8]. This training is a technical training program based on the formation of movement habits involving the nervous system, especially the athletes' intellectuals [9]. The essence of Life Kinetik training is to combine different motion activities that apply a variety of basic movements that activate and relate to cortical parts that can improve athlete efficiency throughout the training process [10].

Athletes tend not to experience creative thinking processes and find it difficult to solve problems quickly at important beneficial moments due to conventional training that tends to be monotonous and boring. Athletes cannot control muscles for efficient exercise, including making the right, fast, and accurate decisions [9]. This condition is important to be resolved immediately if not then the development of football in our country Indonesia will continue to decline, and athletes' achievements will not develop rapidly.

Real conditions that can be used to reference that in European Countries, Life Kinetik training is not new in the training process. All sports communities are familiar with this training. One of the amazing things is that this training has developed rapidly for various purposes, including sports, school, work environment, and even the wider community, ranging from children, adults, parents, sick people, and professionals, to improve performance. People in European countries apply Life Kinetik training to improve various goals including creativity, concentration, memory, confidence, and even use for the healing process from illness [11].

Previous studies conducted by experts include [9] explaining that Life Kinetik training increases the effectiveness of motion and psychological abilities that help increase the effectiveness of the training process [10] explained, children aged 15 years belonging to young athletes practiced 60 minutes of Life Kinetik for eight weeks, the results showed that exercise can improve the sharpness of vision of athletes. Previous studies have suggested that elite football athletes who perform Life Kinetic training for 15-30 minutes in six weeks benefit athletes, including increased concentration, increased reaction speed, and the ability to reduce athlete's error [10]. Research conducted by Duda [9] of 27 students at the German education center showed that the Life Kinetik training carried out 6-20 minutes for four weeks, could improve motion performance and cognitive ability.
From some of these studies, it is clear that Life Kinetik training provides exceptional benefits for improving athlete performance. But in Indonesia, Life Kinetic training is still unfamiliar among coaches and athletes. This exercise has not been widely applied in the training process to improve psychological abilities and football skills. This study aims to examine further the effect of Life Kinetic training on increasing concentration and playing football skills.

\section{Methods}

\section{Participants}

The experimental method is the right method used to solve the problem in this study. In this study, researchers wanted to try out the Life Kinetik and conventional training exercises to improve concentration and football playing skills. The subjects in this study were male football athletes in one of the state universities in Indonesia. The subjects were aged between 18 years and 19 years, with a total of 90 people. The research subjects were taken randomly by applying the subject's procedure, namely through random selection taken as many as 40 people. Through random assignment, 40 people were divided into two groups of subjects namely the experimental and control groups. Each group of subjects with a total of 20 people. In the experimental group, subjects were treated with Life Kinetik training, while the control group was subject given conventional training treatment, which is the exercise commonly given during the training process.

\section{Measurement}

In this study, several dependent variables must be measured, namely the concentration variable and the variable of football playing skills. Concentration variables were measured using the Concentration Grid Test (CGT) instrument (12). This instrument has a validity of 0.76 and a reliability of 0.79 . Whereas the dependent variable of football playing skills was measured using The Games Performance Assessment Instrument (GPAI) from Metzler. This instrument consists of five aspects: decisions made, skill execution, support, adjustment, and game performance. After testing, it turns out that this instrument has a validity of 0.82 and a reliability of 0.90 .

\section{Design}

The design used in this study is the pretest-posttest control group design. In this design, before the researchers give treatment to the subject, they conduct a preliminary test to see the subject's initial ability in the variables of concentration and football playing skills. After the initial test is done, then the treatment is given to the subject 12 
times. After the treatment is given, it is continued with the final test, to see an increase in concentration ability and football playing skills due to the treatment given.

\section{Data Analysis}

The data analysis technique used by researchers in this study was a non-parametric test utilizing Man Whitney test through SPSS for windows 21 version program. The reason is that some of the data, after being tested by the analysis requirements test (normality and homogeneity test), then some of the data is declared abnormal.

\section{Results}

Data were collected through the measurement process, then researchers processed and analyzed using a statistical approach. The data that the researchers analyzed in this study were data on concentration ability and football playing skills. Data from this study were described in the form of data from calculating the mean value of the gain score, and the standard deviation of each variable study. The results of calculating the mean of each study variable's gain score and standard deviation can be seen in Table 1 .

Table 1. The results of the calculation of the mean of the gain score and standard deviation

\begin{tabular}{ccccc}
\hline Group & Variabel & N & Mean & SD \\
\hline \multirow{2}{*}{ Experimental } & Concentration & 20 & 4.400 & 1.759 \\
& Play Skills & 20 & 0.013 & 0.015 \\
\multirow{2}{*}{ Control } & Concentration & 20 & 2.750 & 1.164 \\
& Play Skills & 20 & 0.007 & 0.013 \\
\hline
\end{tabular}

The calculation results in Table 1 show that the mean of the gain score in the experimental group is higher than that of the control group. It is shown that the group of subjects given Life Kinetik training is better than the group of subjects given conventional training. Likewise, when viewed from the calculation of the mean value ranking based on the calculation of non-parametric tests, as shown in Table 2.

Table 2. The results of the calculation of the mean rank in the two study groups

\begin{tabular}{ccccc}
\hline Group & Variable & N & $\begin{array}{c}\text { Mean } \\
\text { Rank }\end{array}$ & $\begin{array}{c}\text { Sum of } \\
\text { Ranks }\end{array}$ \\
\hline \multirow{2}{*}{ Concentration } & Life Kinetik & 20 & 25.98 & 519.50 \\
& Conventional & 20 & 15.03 & 300.50 \\
\multirow{2}{*}{ Play Skills } & Life Kinetik & 20 & 24.53 & 490.50 \\
& Conventional & 20 & 16.48 & 329.50 \\
\hline
\end{tabular}

Table 2 shows that subjects who were trained with the Life Kinetik training obtained mean ranking better than the scores of subjects who were trained with conventional training. Furthermore, to see the increased effect of the two training on increasing concentration and football playing skills, a similarity test of two was used using the paired t-test. This test is carried out to see an increase in the initial test score and the final test in the two study groups.

Based on the results of the paired t-test, it turns out that the significance of the research variables in the experimental group in both research variables obtained significance $p=0.00<0.05$, thus it can be concluded that there is a significant influence on the Life Kinetik training on improving concentration and playing football skills. Whereas in the control group, based on the results of the paired t-test, the significance was obtained $\mathrm{p}=0.00<0.05$ dan $\mathrm{p}=0.10<0.05$. Thus, the research can be concluded that there is a significant influence on conventional training on improving concentration and playing football skills. To see the difference in the two training influences, a difference in the two average tests is then performed using the Mann Whitney Test. The results of the calculations can be seen in Table 3 .

Table 3. Mann Whitney Test calculation results

\begin{tabular}{ccc}
\hline & Concentration & $\begin{array}{c}\text { Play } \\
\text { Skills }\end{array}$ \\
\hline Mann-Whitney U & 90.500 & 119.500 \\
Wilcoxon W & 300.500 & 329.500 \\
Z & -3.014 & -2.254 \\
Asymp. Sig. (2-tailed) & .003 & .024 \\
Exact Sig. [2*(1-tailed Sig.)] & $.002^{\mathrm{b}}$ & $.028^{\mathrm{b}}$ \\
\hline
\end{tabular}

The Mann-Whitney Test's calculation in Table 3 shows that the concentration variable the significance value is obtained $\mathrm{p}=0.003<0.05$, on the variable of playing football skills, obtained significance $p=0.024<0.05$. It can be concluded that there is a significant effect between Life Kinetic training and conventional training on increasing concentration and playing soccer skills. Based on the acquisition of the mean and the acquisition of the mean (mean rank) of the two research variables, it turns out that the scores on the Life Kinetik training are better than the scores on conventional training. Furthermore, it can be concluded that Life Kinetik training is better than conventional training on increasing concentration and soccer playing skills.

\section{Discussion}

Life Kinetik Training influences increasing concentration because Life Kinetik training is a dynamic exercise that involves three important aspects, namely motor activity, cognitive challenges, and visual perception [8]. If the activity is carried out continuously, it is very good to improve cognitive function. Some reasons presented by experts include, [13] explains that; Some reasons presented by experts include, [13] explains that; Physical activity carried out continuously can increase blood circulation to the brain, so that the nerves of individuals can get more oxygen and nutrients; Physical 
activity can stimulate the production of the dophamine hormone, which is one of the neurotransmitters that can improve the mood of someone involved in the activity [13]. In addition to the hormone dopamine also triggers the growth of the hormone serotonin, a hormone that can arouse enthusiasm to achieve goals or targets [10]. If Life Kinetik training is done in an adequate amount that is $40-60 \%$ with a pleasant atmosphere, then the training can increase the production of new cells in the brain [8]. The growth of new cells in the brain (neurogenesis) is highly correlated with one's memory ability [14].

From the results of a study conducted by the University of California neurologist Irvine, it is found that exercise can trigger neurotrophic release from the brain (BDNF: brain-derived neurotrophic factor) a natural material that can improve cognition, by encouraging the ability of neurons to communicate one another. Related to the same thing, [15] also explained, that BDNF is produced and secreted in the brain to regulate the cellular processes of proliferation, development and differentiation. It is synthesized by both neurons and glial cells and allows neurons to receive adequate nutrition to grow, develop or regenerate themselves. Throughout development, BDNF expression is strictly controlled, and its alteration can cause morphological and functional changes in the brain throughout the life course [16].

The results of Irvine's study found that aged rats who exercise every day found that BDNF increased in various brain areas, including the hippocampus, which is important in-memory processing. BDNF seems to accelerate long-term potential (LTP: long-term memory processing), or form memory in young mice [13]. Life Kinetik Training is a training method that can form new synapses in the brain [9]. It can improve cognitive function and long-term memory processes [17], while also increasing connectivity in parts of the brain that allow involvement in tasks in the training process [8]. Therefore, kinetic life training is very good for influencing the mind, mood, memory, and overall health [18].

The use of Life Kinetik training turns out to provide wider benefits for the community so that children can do this training, adults, parents or the elderly [9], the sick for the healing process, and professionals including athletes in sports achievement [10], because it functions very well on our brains especially in the formation of new syntax in the brain [19]. In another study, it is explained that physical activity in the treatment of improvement in cognitive function aspects in older adults is becoming increasingly well established. Furthermore, acute bouts of well managed physical exercise may facilitate certain aspects of information processing in adults [17]. In further studies with a longitudinal approach, it was found that older adults that participate in physical activity show a less cognitive decline over two-to 10-year follow-up periods. Cardiorespiratory fitness assessed at baseline predicted cognitive performance six years later in various cognitive domains like working memory, processing speed, attention, and general mental functioning [16].

Furthermore, Life Kinetik training contributes to improving cognitive function, specifically in children [20]. Cognitive abilities are beneficial to one's active lifestyle [21], improving executive functions of controlling, planning, decision making, working memory, and cognitive flexibility [22]. The function of cognition is needed for performance and in daily activities. It is important to develop cognition and movement development [22] and social and emotional relationships throughout life [23]. Working memory is very important for learning, controlling attention, and both are processes that are directly related to academic achievement [24]. In a Neuroimaging study, it is indicated that: The brain regions previously thought to be exclusively related to motor activity (cerebellum and basal ganglia) or cognition (PFC) are co-activated during the execution of specific cognitive or motor activities [25]. The relationship between PFC neurons and the cerebellum and the basal ganglia is directly involved in controlling coordination exercises [26]. Besides, physical exercise, especially in the Life Kinetik training method, can increase blood volume to the brain [23], basal ganglia volume [21], and increase the release of neurotransmitters (e.g., norepinephrine, dopamine, and serotonin), and trophic factors, such as the brain-derived neurotrophic factor [18]. This is a molecular response to physical activity that increases synaptogenesis, angiogenesis, and neurogenesis, specifically in the hippocampus [27].

Based on the neuroscience approach, it is believed that the function and growth of the brain are the result of the physical exercise process [7], in its implementation, the brain to be able to function properly requires basic elements, namely oxygen, blood, and water, and this is very important for learning. However, physical activity must be carried out with at least $60 \%$ intensity, namely physical activity carried out pleasantly and not tiring the culprit [8]. Therefore, pleasant physical activity is very influential on brain function, especially in improving the ability of concentration and intelligence that is important in learning football playing skills. Study [13] explain, movement and physical engagement enables oxygen to be carried to the brain for efficient functioning and learning. Some studies have found that: Children's attention and learning improve immediately following physical activity that produces moderate levels of arousal [28].

Concerning improving football playing skills, Life Kinetik training is indeed a familiar exercise in European countries' football circles. Athletes and trainers do Life Kinetik Training to improve their performance [10]. This exercise is very good so that athletes stay focused on doing their job, always have a good perception, and can make decisions quickly and accurately.

The effect of Life Kinetik training on improving football playing skills. The mastery of football playing skills must 
be with various abilities, both physiological and psychological abilities. Physiologically athletes must have good physical conditions, including strength, flexibility, endurance, speed, agility, coordination, and cognitive function abilities [27]. Football athletes who can display their skills and are intelligent in making decisions in play due to developing the brain's basic abilities, which is done by developing sensory-motor skills through motion activities. One of them is Life Kinetik training. The process of association and sensory integration and sensory-motor interaction is a key foundation for success in the learning process, especially learning sports skills, and can be implemented through physical activities [29].

Anatomically, the brain stem contains a structure called reticular formation that is very complicated and has a relationship with all important structures of the brain [30]. The brain stem is vital for human life because it regulates breathing, heart rate, digestion, and monitoring awareness, alertness, attention, and concentration. The cerebellum also deals with the brain stem in the regulation of fine and precise motion coordination. There are centers (limbic systems) in subcortical structures for the regulation of responses and emotional development. Memory capabilities (memory) are also monitored in this area. Once the importance of the brain's basic abilities appears in the involvement of many structures that are vital and essential for the development of the learning process, especially learning football playing skills. This structure's development can only be done through a process of association and sensory-motor integration that is already included in the physical activity program. [29] explains the process of association and sensory integration and sensory-motor interaction carried out through physical activity can produce the final product in the form of increased ability to concentrate, self-confidence, self-control, self-esteem, memory, academic learning, abstract thinking, and introduction to specialties on each side of the body and brain.

In this study, Life Kinetik training was better than conventional training, because Life Kinetik trained the brain with various cognitive challenges and challenging motion patterns that spurred the brain to overcome these challenges. Whereas in conventional training, the training process does not look like life kinetik training, but it tends to be monotonous and does not contain complex task challenges. It does not thoroughly provide a stimulus to the brain while the brain is an important part of achieving the best performance.

\section{Conclusion}

Based on data analysis results, there are significant differences in the effect of Life Kinetik training and conventional training on increasing concentration and football playing skills. Life Kinetik Training is better than conventional training at increasing concentration and football playing skills. It is very reasonable because Life Kinetik training can stimulate brain cells' growth, especially in the hippocampus that functions like memory. Life Kinetik Training can stimulate two parts of the brain, namely the left brain and right brain. In conventional training, such a process does not occur even though exercise's dominance involves the function of the left brain. Football athletes are required concentration so that it affects the ability to make decisions in football playing skills, where athletes are focused and shape the ability to multitask in flaying situations. Therefore, the authors would like to recommend coaches and athletes in the football to use Life Kinetik in the training process because it can improve athlete concentration and football playing skills.

\section{Acknowledgments}

Research group members namely Patriana Nurmansyah Awwaludin, Yusuf Hidayat, Novrizal Achmad Novan, and football athletes subjects in one of the State Universities in Indonesia are proplerly acknowledged.

\section{REFERENCES}

[1] Heinen. Do Static-Sport Athletes and Dynamic-Sport Athletes Differ in Their Visual Focused Attention? Sport J. 2011; 14(1): 2011 .

[2] Brewer, W. B. Sport Psychology: Handbook of Sport Medicine and Science. Wiley-Blackwell. 2008; 2008.

[3] Weinberg, R. S., \& Gould D. Foundations of Sport and Exercise Psychology (6th ed). Human Kinetics; 2015.

[4] Blumenstein B, Orbach I. Periodization of Psychological Preparation within The Training Process. Int J Sport Exerc Psychol. 2020; 18(1):13-23.

[5] Blann, F. W., Shelley, G., \& Gates SC. Marketing sport psychology consulting services. J Sport Psychol Action. 2011; 2(1):33-52. 10.1080/10413200701784841.

[6] Jones MI, Harwood C. Psychological momentum within competitive soccer: Players' perspectives. J Appl Sport Psychol. 2008;20(1): 57-72.

[7] Drust, T. Reilly and NTC. Physiological Responses to Laboratory-Based Soccer-Specific Intermittent \& Continuous Exercise Physiological Responses to Laboratory-Based Soccer-Special Intermittent and Continuous Exercise. 2013;(September): 37-41.

[8] Demirakca T, Cardinale V, Dehn S, Ruf M, Ende G. The Exercising Brain: Changes in Functional Connectivity Induced by an Integrated Multimodal Cognitive and WholeBody Coordination Training. Hindawi Publ Corp. 2016;1(1):1-11. 
[9] Henryk D. Application of Life Kinetik in The Process of Teaching Technical Activities to Young Football Players. J Kinesiol Exerc Sci. 2015;71(25):53-63.

[10] Lutz. Perform Better with Life Kinetik Life. Kinetik Presentation NSCAA Convention. 2017.

[11] Lutz H. Life Kinetik. Gehirntraining durch Bewegung. 2014. 1-111 p.

[12] Jean W. Applied Sport Psychology: Personal Growth to Peak Performance Second Edition. Mayf Publ Co. 1993;1993.

[13] Jensen E. Pembelajaran Berbasis Otak: Paradigma Pengajaran Baru. Jakarta PT Indeks. 2008;2008.

[14] Kitabatake Y, Sailor KA, Ming G, Song H. Adult Neurogenesis \& Hippocampal Memory Function: New Cells , More Plasticity, New Memories? Neurosurg Clin N Am. 2007; 105-13.

[15] Gomez, P, F., Hillman C. The Influence of Exercise on Cognitive Abilities. Compr Physiol. 2013;3:28-43.

[16] Bherer, L., Erickson, KI., Liu-ambrose T. A Review of the Effects of Physical Activity and Exercise on Cognitive and Brain Functions in Older Adults. J Aging Res. 2013;(Article ID 657508):8.

[17] Thomas M. The Effect of Different Movement Exercises on Cognitive and Motor Abilities. Adv Phys Educ. 2012;2(4):172-8.

[18] Dishman, R.K., Berthoud, H.R., Booth, F.W., Edgerton, V.R., Fleshner MR. Neurobiology of Exercise, Obesity. 2006;14:345-56.

[19] Bellie, J K. Life Kinetik: Brain Training for The Pros "A Work Out for The Brain. FIFA. In: Magazine. England: FIFA, A Work Out for The Brain; 2016. p. 1-68 pages.

[20] Masley S., Roetzheim R. GT. Aerobic Exercise Enhances Cognitive Flexibility. J Clin Psychol Med Settings. 2009;16(April): 186-93.
[21] Chaddock L., Erickson K. I., Prakash R. S., Voss M. W., VanPatter M., Pontifex M. B. et al. A Functional MRI Investigation of The Association Between Childhood Aerobic Fitness and Neurocognitive Control. BiolPsychol. $2012 ; 260-8$.

[22] Miyake A., Friedman N. P., Emerson M. J., Witzki A. H., Howerter A. WTD. The unity and diversity of executive functions and their contributions to complex "Frontal Lobe" tasks: a latent variable analysis. Cogn Psycho 2000;4(1):49-100.

[23] Pereira A. C., Huddleston D. E., Brickman A. M., Sosunov A. A., Hen R., McKhann G. M. et al. An in Vivo Correlate of Exercise-Induced Neurogenesis in The Adult Dentate Gyrus. Proc Natl Acad Sci USA 104. 2007;10(4):5638-43.

[24] Redick T. S. ERW. Working Memory Capacity \& Attention Network Test Perfor-mance. Appl Cogn Psychol. 2006;20:713-21.

[25] A D. Close Interrelation of Motor Development and Cognitive Development and of The Cerebellum and Prefrontal Cortex. Child Dev. 2000;7(1):44-56.

[26] Budde H., Voelcker-Rehage C., Pietrabyk-Kendziorra S., Ribeiro P., Tidow G., Pietraßyk- Kendziorra S. et al. (2008). Acute Coordinative Exercise Improves Attentional Performance in Adolescents. Neurosci. 2008;219-23.

[27] Johann, V.E. et al. Effects of Motor-Cognitive Coordination Training and Cardio-vascular Training on Motor Coordination and Cognitive Functions. Psychol Sport Exerc. 2016;24(August):118-27.

[28] Tomporowski, P D. Cognitive \& Behavioral Responses to Acute Exercise in Youth: a Review. Pediatr Exerc Sci. 2003;348-59.

[29] Kusumoputro. Pendidikan Jasmani dapat Menopang Proses Belajar: Tinjauan dari Segi Organisasi Otak. Harian Kompas.

[30] Viswejan U. Impact of Ladder Training on Agility Balance and Coordination Among School Students. 2017;229-31. 